\title{
What is the Lived Experience of Trafficked Persons in Nigeria?
}

\author{
Abi Badejo, Sharyn Rundle-Thiele, and Krzysztof Kubacki
}

\begin{abstract}
This study aims to understand the lived experiences of individuals who have been trafficked both within and outside of Nigeria for the purpose of sexual exploitation and domestic labour. Interview questions were guided by cultural norms discussed in human trafficking literature. Results of the study reject the notion that women trafficked abroad for sex work are victims who are often exploited by their traffickers. While evident in some cases and certainly the view propagated by the media and activist groups, this chapter reveals exploitation is minimal. However, in the case of individuals being trafficked within the country, exploitation is prevalent and individuals are at the mercy of relatives and madams who exploit them for their own gain. Further, contrary to widely held beliefs that individuals trafficked are kidnapped by strangers against their will, this chapter identifies that the trafficked are introduced to the trafficker by someone within their sphere of influence including friends and close relatives. These results can inform future social marketing interventions targeting both individuals at risk and the important others who surround them (midstream) in order to reduce the prevalence of human trafficking. Limitations and future research directions are outlined.
\end{abstract}

\footnotetext{
A. Badejo $(\square) \bullet$ S. Rundle-Thiele $\bullet$ K. Kubacki

Griffith University, Nathan, Australia

e-mail: abi.badejo@griffithuni.edu.au; s.rundle-thiele@griffith.edu.au;

k.kubacki@griffith.edu.au

L. Petruzzellis, R.S. Winer (eds.), Rediscovering the Essentiality of Marketing, Developments in Marketing Science: Proceedings of the Academy of Marketing Science, DOI 10.1007/978-3-319-29877-1_84
} 